\title{
RESENHA
}

\section{O ENSINO E A APRENDIZAGEM DE MATEMÁTICA NOS CICLOS DE FORMAÇÃO SUPERIOR}

\author{
Chaiane de Medeiros Rosal \\ Fabiano Fortunato Teixeira dos Santos²
}

GODOY, Elenilton Vieira; GERAB, Fábio (Orgs.). Ensino e aprendizagem de matemática na educação superior: inovações, propostas e desafios. Rio de Janeiro: Alta Books, 2018. 320 p. ISBN 978-85-508-0274-9

O livro Ensino e aprendizagem de matemática na educação superior: inovações, propostas e desafios, publicado em 2018 pela Alta Books, foi organizado pelos professores Elenilton Vieira Godoy, do departamento de Matemática e do Programa de Pós-Graduação em Educação em Ciências e Matemática da Universidade Federal do Paraná (UFPR), e Fábio Gerab, professor titular e chefe do Departamento de Matemática do Centro Universitário da Fundação Educacional Inaciana "Padre Sabóia de Medeiros" (FEI).

A obra apresenta um compilado de 11 trabalhos que constituem seus capítulos, todos relacionados com o ensino e a aprendizagem de Matemática ao longo dos ciclos de formação na educação superior, de autoria de diversos autores. Todos os tópicos são resultantes de observações e experiências realizadas no âmbito dos cursos de graduação em Administração, Ciência da Computação e Engenharia do Centro Universitário FEl. Essa instituição foi escolhida pelo fato de que, é nela que o Grupo de Educação Matemática e Matemática no Ensino Superior

\footnotetext{
1 Doutora em educação. Universidade Federal de Goiás (UFG). Orcid iD: http://orcid.org/0000-0001-8609-3487. E-mail: chaiane@ufg.br

2 Doutor em Matemática. Universidade Federal de Goiás (UFG). Orcid iD: http://orcid.org/0000-0002-4455-8175. E-mail: fortunato@ufg.br
} 
(GEMMES), instituído em 2016 no Diretório de Grupos de Pesquisa do Conselho Nacional de Desenvolvimento Científico e Tecnológico (CNPq), desenvolve pesquisas sobre diversos aspectos da Educação Matemática no âmbito da educação superior, especialmente sobre: Ensino e Aprendizagem da Matemática; Epistemologia e História da Matemática; Matemática Aplicada e Computacional; e Tecnologias Educacionais no Ensino de Matemática.

O livro é dividido em quatro partes. A primeira delas, intitulada $O$ Ensino e a Aprendizagem de Matemática na Transição Educação Básica/ Educação Superior, traz quatro capítulos que discutem temas como: perspectiva do aprendizado de Matemática; contribuição da Matemática e do ensino do Desenho Geométrico com utilização de softwares para despertar o interesse pela Engenharia; e as atitudes e desempenho em Cálculo Diferencial e Integral. Vale ressaltar que, nesta primeira parte da obra em questão, o foco foi dado aos estudantes do curso de Engenharia do Centro Universitário FEI.

O capítulo 1, A Transição Ensino Médio - Ensino de Engenharia na Perspectiva do Aprendizado de Matemática: um Diagnóstico sob a Ótica do Estudante, escrito por Elenilton Vieira Godoy e Fábio Gerab, apresenta os resultados de um estudo feito com estudantes do segundo ao quarto semestres dos cursos de Engenharia, sobre as seguintes questões: perfil discente, a graduação, a formação na educação básica, o processo de ensino e aprendizagem, o acolhimento proporcionado pela instituição de ensino, a percepção da utilidade das escolas de reforço fora das instituições de educação superior e a dispersão em sala de aula. O objetivo é caracterizar os estudantes dos cursos de Engenharia; mapear suas dificuldades na área de Matemática; compreender como o processo de ensino-aprendizagem poderia auxiliá-los no cotidiano; conhecer suas experiências de sucesso e/ou fracasso; e, a partir disso, coletar sugestões para contribuir com o aprendizado dos mesmos.

No capítulo 2, Contribuição da Matemática no Ensino Médio para Despertar o Interesse pela Graduação em Engenharia, o autor Custódio 
Thomaz Kerry Martins apresenta um projeto desenvolvido com o intuito de promover o interesse dos estudantes do ensino médio pela Engenharia, por meio da valorização de problemas matemáticos concernentes a situações próximas da realidade profissional de um engenheiro, ou seja, referentes a situações concretas.

O capítulo 3, Despertando o Interesse pela Engenharia: o Ensino do Desenho Geométrico no Ensino Médio, com a Utilização de Softwares, produção de Armando Pereira Loreto Junior, traz um estudo sobre o projeto denominado Forma-Engenharia, que busca conscientizar os estudantes do ensino médio sobre a importância do Desenho Geométrico para subsidiá-los em disciplinas básicas dos cursos de Engenharia, caso venham cursá-los. Para tanto, promove-se a construção do conhecimento matemático para estudantes do ensino médio, principalmente de conteúdos de Desenho Geométrico, Perspectiva, Geometria Descritiva e Desenho Técnico, utilizando-se os softwares Cabri Geometry II Plus e GeoGebra.

No capítulo 4, As Atitudes e o Desempenho em Cálculo Diferencial e Integral de Estudantes de Engenharia, Marcos Antonio Santos de Jesus delineia os resultados de um estudo feito com base em entrevistas com estudantes matriculados no primeiro ano do ciclo básico dos cursos de Engenharia, os quais estavam cursando a disciplina Cálculo Diferencial e Integral. Para análise dos dados, os estudantes foram categorizados em ingressantes (cursando a disciplina pela primeira vez) e dependentes (cursando a disciplina pela segunda vez), e também por turno (diurno e noturno).

Já a segunda parte da obra, denominada Experiências Pedagógicas nas Etapas Iniciais da Educação Superior, é composta por dois capítulos que apresentam resultados de experiências metodológicas utilizadas com alunos na etapa inicial da graduação nas disciplinas de Geometria Analítica e Cálculo Diferencial e Integral.

No capítulo 5, Geometria Analítica: Proposta de Abordagens com Exploração de Registros Semióticos nos Ambientes Papel e Lápis e Computacional, os autores Mônica Karrer e Tiago Estrela de Oliveira, partindo 
do princípio de que a Geometria Analítica está presente no início de vários cursos da área de Ciências Exatas, realizaram um estudo que consiste na proposição de atividades/experimentos desse campo do saber, especialmente sobre os tópicos Vetores e Base no Plano. O estudo foi realizado com estudantes do ciclo básico do curso de Engenharia, que já tiveram contato com o tema proposto, mas sem o uso do recurso computacional. As atividades foram desenvolvidas tanto no GeoGebra como no papel e lápis, de modo a propiciar registros diversos de representações semióticas, com vistas a exigir dos alunos uma postura mais ativa na realização das atividades/experimentos.

No capítulo 6, Aprendizagem Significativa no Cálculo Diferencial e Integral: Relato de Experiência com a Abordagem de Problemas de Taxa de Variação na Formação de Engenheiros, Cláudio Dall'Anese e Paulo Henrique Trentin, considerando o baixo desempenho acadêmico em Cálculo Diferencial e Integral, descrevem a experiência da propositura de uma sequência didática, com atividades a serem desenvolvidas, a estudantes da disciplina Cálculo I dos cursos de Engenharia. O objetivo é contribuir com o desenvolvimento de uma prática pedagógica alternativa ao introduzir os conceitos de Cálculo Diferencial e Integral, assim como explorar o conceito de derivada, considerando a noção de taxa de variação.

A terceira parte do livro, Perspectiva Histórica no Ensino de Matemática, por sua vez, é formada de dois capítulos que apresentam experiências e histórias referentes à Educação Matemática.

O capítulo 7, Inquietações e Possibilidades: Excertos de Experiências no Ensino e na Aprendizagem das "Matemáticas" para uma "Educação Matemática", produzido por Paulo Henrique Trentin, traz uma discussão que articula três principais aspectos, quais sejam: o papel do material escrito na prática social do professor de Matemática; a presença de fragmentos da História da Matemática nos livros didáticos de Matemática; e a atribuição de significados idiossincráticos e o mapeamento de conceitos, por professores e estudantes, atribuídos a determinados constructos. 
No capítulo 8, O Curso de Engenharia Operacional da Faculdade de Engenharia Industrial (1963-1977), elaborado por Armando Pereira Loreto Junior, apresenta-se o histórico de criação do curso de Engenharia Operacional da Faculdade de Engenharia Industrial, desde sua criação até sua extinção. Foram abordados aspectos como: estrutura física da instituição, currículo do curso, e embates políticos entre favoráveis e contrários à criação/manutenção do curso.

Por fim, a quarta e última parte da obra em questão, Conexão entre o Aprendizado de Matemática e as Demais Áreas do Conhecimento na Educação Superior Matemática, é constituída de três capítulos, os quais discutem métricas de desempenho na graduação, abordagem integrada de técnicas de Cálculo Numérico e Modelagem Matemática, conhecimentos matemáticos esses empregados em diversas áreas do saber.

No capítulo 9, Utilização de Métricas Acadêmicas no Aprimoramento de Cursos de Graduação, de autoria de Fábio Gerab, é tecida uma discussão sobre a importância dos resultados das avaliações externas e internas (análise das interações curriculares, de desempenho acadêmico, de evasão e titulação em cursos) para o aprimoramento do processo pedagógico, e, logo, melhoria dos cursos de graduação. Entende-se que as informações obtidas por meio desses resultados são capazes de evidenciar comportamentos e características de um curso, assim como identificar necessidades pedagógicas e curriculares de adequação.

No capítulo 10, Estudo de Caso com Abordagem Integrada de Técnicas de Cálculo Numérico em Curvas Tensão-Deformação de um Aço Inoxidável Ferrítico e Subsequente Projeto de Conformação Mecânica a Frio por Trefilação, de autoria de Júlio César Dutra e Tiago Estrela de Oliveira, são demonstrados os resultados de um estudo realizado com estudantes dos cursos de Engenharia, na etapa intermediária de suas formações, já detentores de conhecimentos de Cálculo e Programação, sobre o conteúdo de propriedades mecânicas. Foi proposta uma abordagem integrada de técnicas de Cálculo Numérico e Modelagem Matemática com o propósito de que esses estudantes fossem instados a desenvolver competências, 
habilidades e atitudes relacionadas à temática, quando submetidos a um trabalho que demanda mais que interpretação de resultados, mas também análise, avaliação e criação de projetos.

Por fim, o capítulo 11, Modelagem Matemática Aplicada ao Estudo de Caso, elaborado por Antonio Carlos Gracias, apresenta os resultados de um estudo feito utilizando-se um modelo logístico de Verhulst para descrever e modelar a importação e a produção de gasolina do Brasil. O estudo foi feito tendo como base dados do Balanço Energético Nacional de 2012.

Ressalta-se que este se trata de um livro organizado em capítulos, os quais se encontram desarticulados, a não ser por uma temática central que perpassa todos, que é o ensino e aprendizagem de Matemática na educação superior. Até mesmo os próprios organizadores da obra, em seu prefácio, reconhecem que essa falta de conexão e interdependência das partes "podem enfraquecê-la".

Mesmo assim, o livro apresenta resultados de experiências interessantes, que podem inspirar novas práticas, e contribuir tanto para atrair jovens egressos do ensino médio para as áreas de exatas na educação superior, como também para a superação das dificuldades e desafios que envolvem o ensino e a aprendizagem de Matemática em todos os níveis de ensino. No mais, esta produção mostra possibilidades de aplicação da Matemática especialmente nas Engenharias, mas também em outros campos do conhecimento, o que sinaliza que o conhecimento matemático não é restrito ou limitado a uma única área.

Outrossim, a obra ganha relevo por ser resultado do trabalho de um grupo de educadores brasileiros que se empenha em realizar pesquisas com abordagens diversas, mas sempre com o propósito de contribuir para a construção de saberes e experiências que sejam significativas para $\circ$ aprimoramento do ensino e aprendizagem em Matemática no país.

Recebido em: 04 de fevereiro de 2019 Aprovado em: 27 de junho de 2019 